Charlotte M. Chiong, MD, PhD ${ }^{1,2,3}$

Rachel T. Mercado-Evasco, MD ${ }^{3}$

Alessandra E. Chiong, $\mathrm{BS}^{2}$

Mary Ellen C. Perez, MD ${ }^{4}$

Franco Louie L. Abes, MD, MSc ${ }^{1,3}$

Abner L. Chan, MD $1,2,3$

'Philippine National Ear Institute

National Institutes of Health

University of the Philippines Manila

${ }^{2}$ Department of Otorhinolaryngology

College of Medicine - Philippine General Hospital

University of the Philippines Manila

${ }^{3}$ Department of Otolaryngology

Manila Doctors Hospital

${ }^{4}$ Department of Anesthesiology

College of Medicine-Philippine General Hospital

University of the Philippines Manila
Correspondence: Dr. Charlotte M. Chiong

Philippine National Ear Institute, National Institutes

of Health and Ear Unit, Philippine General Hospital

University of the Philippines Manila

Taft Avenue, Ermita, Manila 1000

Philippines

Phone: (632) 5548400

Email: cmchiong@up.edu.ph; charlotte_chiong@yahoo.com

The authors declare that this represents original material that is not being considered for publication elsewhere in full or in part, in print or electronic media; that the manuscript has been read and approved by all the authors, that the requirements for authorship have been met by each author, and that each author believes that the manuscript represents honest work.

Disclosures: The authors signed disclosures that there are no financial or other (including personal) relationships, intellectua passion, political or religious beliefs, and institutional affiliations that might lead to a conflict of interest.

Presented at Philippine Society of Otolaryngology - Head and Neck Surgery Interesting Case Contest, May 22, 2014, Menarini, W Office Bldg, Bonifacio High Street, BGC, Taguig City.

Presented in part at the ASEAN ORL Congress, November 12, 2015, Empress Convention Centre, Chiang Mai, Thailand

\section{Congenital Oval Window Aplasia: An Unusual Cause of Conductive Hearing Loss in an Adult}

ABSTRACT

Objectives: To report a case of congenital oval window aplasia (COWA) in a Filipino adult presenting with unilateral maximal conductive hearing loss and discuss the diagnostic considerations, pathophysiology and management.

\section{Methods:}

$\begin{array}{ll}\text { Design: } & \text { Case Report } \\ \text { Setting: } & \text { Tertiary Public Referral Center } \\ \text { Patient: } & \text { One }\end{array}$

Results: Audiometric evaluation showed a maximal unilateral left conductive hearing loss. High resolution temporal bone $\mathrm{CT}$ showed absence of the oval window on the left along with facial and stapes abnormalities. Exploratory tympanotomy showed an aberrant facial nerve, monopodal and abnormally located stapes and absent oval window. Postoperative hearing gain achieved after a neo-oval window and Schuknecht piston wire prosthesis remained stable over two years.

Conclusion: A congenital minor ear anomaly classified as Cremers Class 4a in which a congenital oval window aplasia was associated with an aberrant facial nerve anomaly and a monopodal stapes is reported. Recent literature supported the view that congenital oval window aplasia can in selected cases be amenable to various surgical approaches and a stable postoperative hearing gain is achievable in the long term.

Keywords: oval window absence, Cremers classification, congenital middle ear

Congenital anomalies of the oval window found in only $0.5 \%-1.2 \%$ of children with conductive hearing loss, are considered a rare cause of congenital hearing loss-- more so in adults where tympanosclerosis, otosclerosis and other acquired conditions predominate.' To the best of our knowledge, congenital oval window aplasia has not been reported in a Filipino adult. Controversy exists with respect to surgical intervention especially in unilateral cases. We report one such case presenting with unilateral maximal conductive hearing loss and discuss the diagnostic considerations, pathophysiology and management. 


\section{CASE REPORTS}

\section{CASE REPORT}

A 37-year-old man reported a history of left-sided hearing loss noticed at age 15 . He initially benefited from several hearing aids (CROS aids included) but hearing loss eventually progressed over the recent six months prior to consultation in a tertiary referral clinic. Two previous specialist consults yielded different opinions regarding possible surgical management. The first specialist considered otosclerosis and advised exploratory tympanotomy while the second assessed the facial nerve anomaly as serious and deemed surgical intervention impossible given the high risk of facial nerve injury. The patient denied a family history of hearing loss, previous ear diseases and vestibular conditions. There was no history of facial nerve paresis and normal facial function (House Brackmann Grade I/VI) was evident.

Otoscopic exam of the tympanic membrane was normal and pneumatic otoscopy showed good mobility. Tuning fork test showed Weber lateralization and negative Rinne in the left with contralateral normal Rinne. Pure tone audiometry revealed a severe conductive hearing loss and maximal air bone gap of $65 \mathrm{~dB}$ in the left and mild high frequency sensorineural hearing loss in the right. (Figure 1) A Type A tympanogram was recorded in both ears. Axial temporal bone high resolution computed tomography (HRCT) showed a malpositioned stapes and an aberrant facial nerve that coursed along the promontory below the putative oval window area (Figure 2), near the round window niche. There was no bony destruction of the malleus or incus and no demonstrable soft tissue densities in the mastoid air cells. Coronal HRCT thin slice temporal bone window cuts revealed an absent oval window (Figure 3) but no round window aplasia was notable. The malpositioned stapes was seen directed more posteroinferiorly relative to the facial nerve canal which was absent in the usual tympanic segment; instead soft tissue was found below the usual area of the oval window. (Figure 4) Magnetic resonance imaging (MRI) showed no evidence of a tumor in the middle ear, internal auditory canals or inner ear, and brain. Various options such as conventional hearing aids, active or passive bone conduction devices (Bone bridge and BAHA) were discussed with the patient, including exploratory tympanotomy to confirm the initial impression of COWA Cremers Type 4a congenital minor ear anomaly. The patient consented to the latter along with possible surgical reconstruction of the hearing mechanism.

A neo-oval window or vestibulotomy (0.6) was performed using a hand perforator (MCO218-6, Microfrance, St. Aubin, France) and a 0.6 $\mathrm{mm}$ Schuknecht wire piston prosthesis (Richards Medical Co., Memphis, TN, U.S.A.) was placed. Intraoperative facial nerve monitoring (NIM 2.0 ( Xomed Minneapolis, MN, U.S.A.) helped map out the exact borders of the facial nerve in the middle ear. (Figures 5 and 6 ) There was no postoperative facial nerve paresis. Postoperative hearing outcomes after one month, one year, and two years (Figure 7) documented the closure of an $\mathrm{AB}$ gap at about $25 \mathrm{~dB}$ which remained consistent over the follow up period.
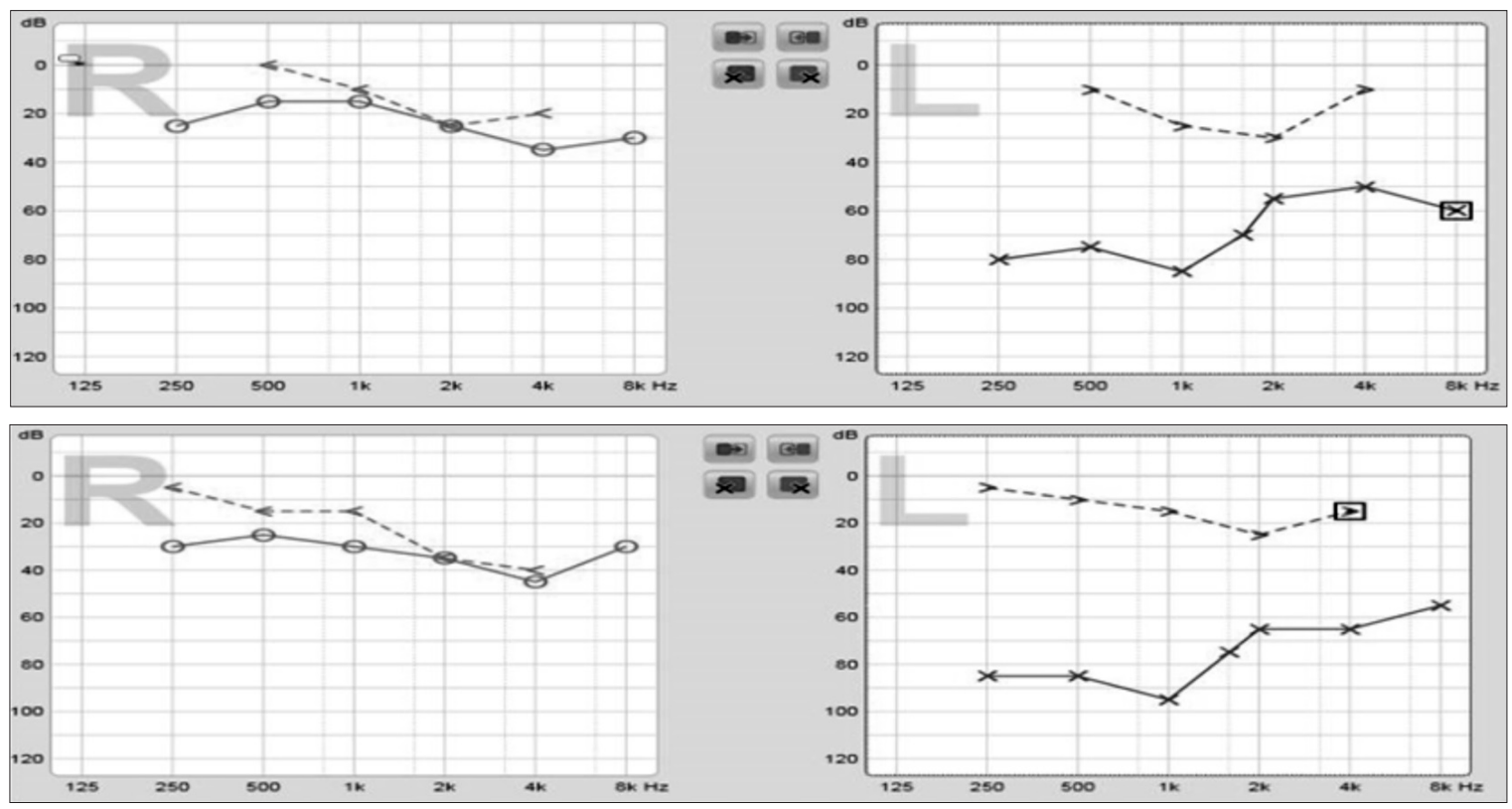

Figure 1. Preoperative audiograms six months apart (January and June 2012) showing severe conductive hearing loss and maximum Air-Bone Gap in the left ear with only a mild high frequency sensorineural hearing loss in the right ear. 


\section{CASE REPORTS}

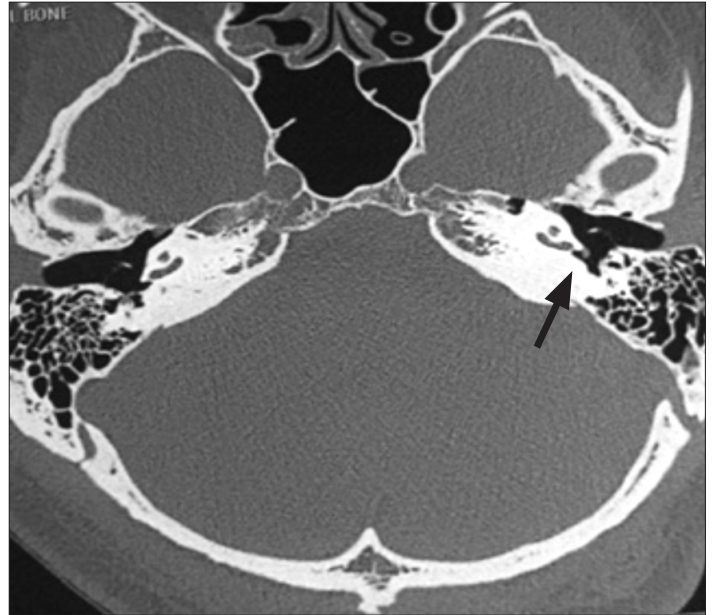

Figure 2. Axial temporal bone $\mathrm{CT}$ of the patient showing the soft tissue (facia nerve over the promontory (solid arrow) at the round window niche area in the left middle ear compared to its usual location in the right.

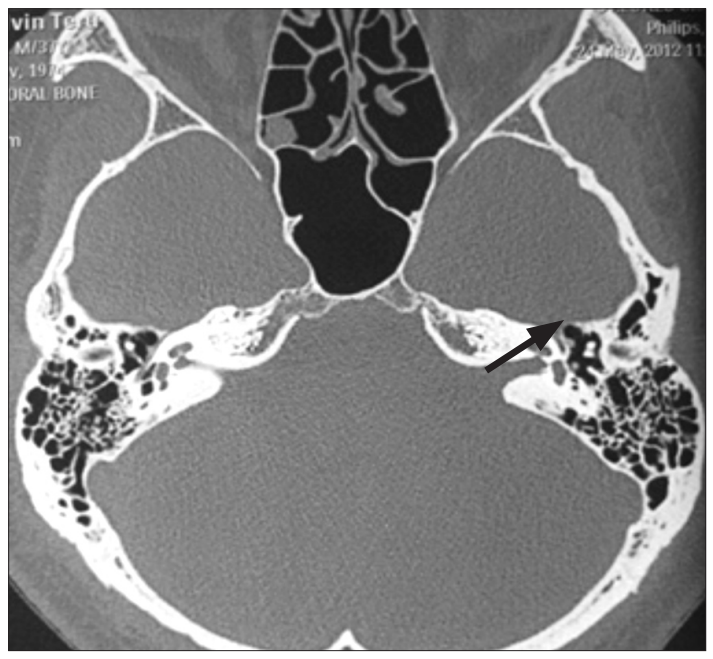

Figure 3. Axial CT of the temporal bone showing absence of the oval window, a malpositioned stapes and the absent tympanic segment of the facial nerve (solid arrow) on the left compared to the normal right side.

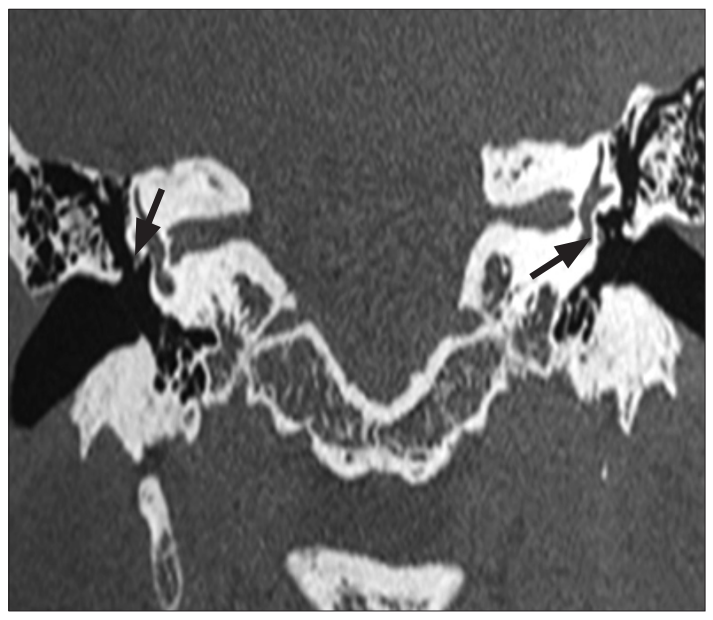

Figure 4. Coronal temporal bone $\mathrm{CT}$ shows the facial nerve soft tissue under the putative absent oval window. The oval window is present on the right side (solid arrow) under the facial nerve in the tympanic segment.
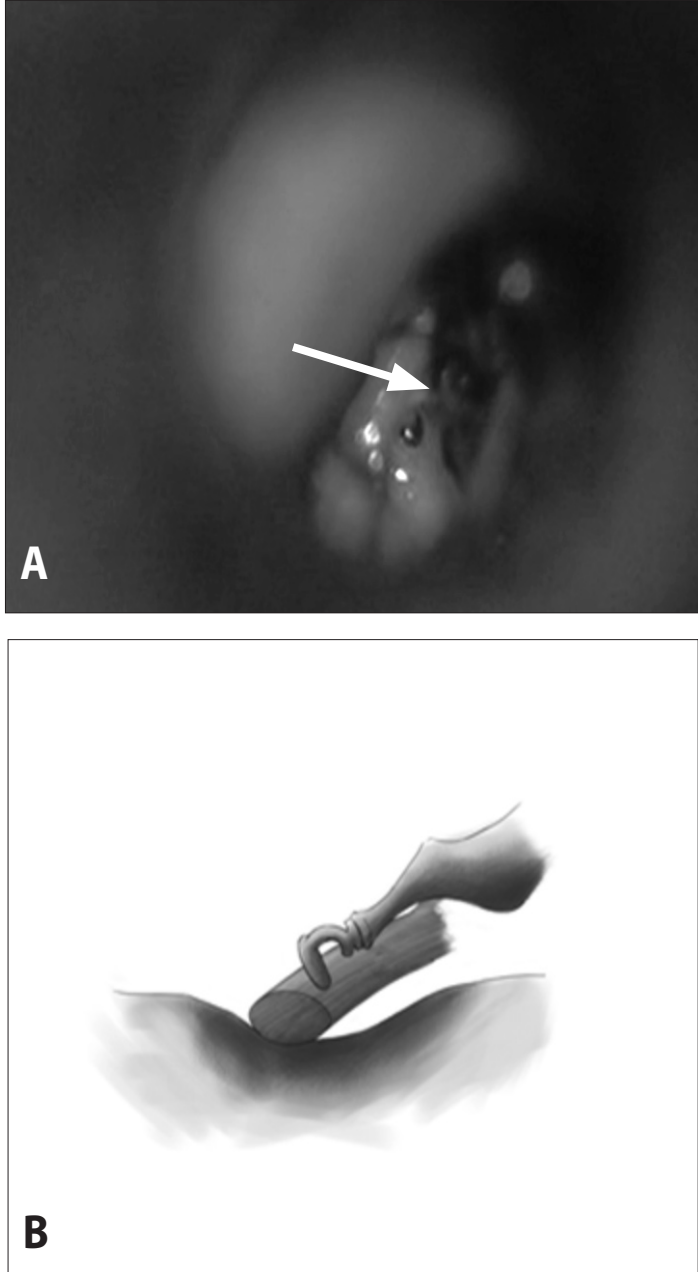

Figure 5. An abnormal monopodal stapes (b) was malpositioned and directed towards the inferior portion towards the sinus tympani (a) and the facial nerve (FN) was found below the area of the putative oval window (arrow).

\section{DISCUSSION}

Congenital minor ear anomalies are classified as Cremers' Type 1 (fixation of stapes footplate alone), Type 2 (stapes footplate fixation with other ossicular anomalies), Type 3 (mobile stapes footplate with other ossicular anomalies) and Type 4 (4a- aplasia of the oval window or round window (4b- dysplasia) with aberrant facial nerve. ${ }^{2}$ Morphodysplasia of autosomal recessive transmission was reported by Sterkers ${ }^{3}$ while to Jahrsdoerfer ${ }^{4}$ the anterior displacement of the facial nerve between the stapes blastema and the otic capsule is responsible for preventing the development of the oval window and lamina stapedialis.

Otoscopy is done to rule out common causes of conductive hearing loss such as otitis media and its sequelae as well as tympanosclerosis or other mass lesions in the middle ear. Puretone audiometry 


\section{CASE REPORTS}
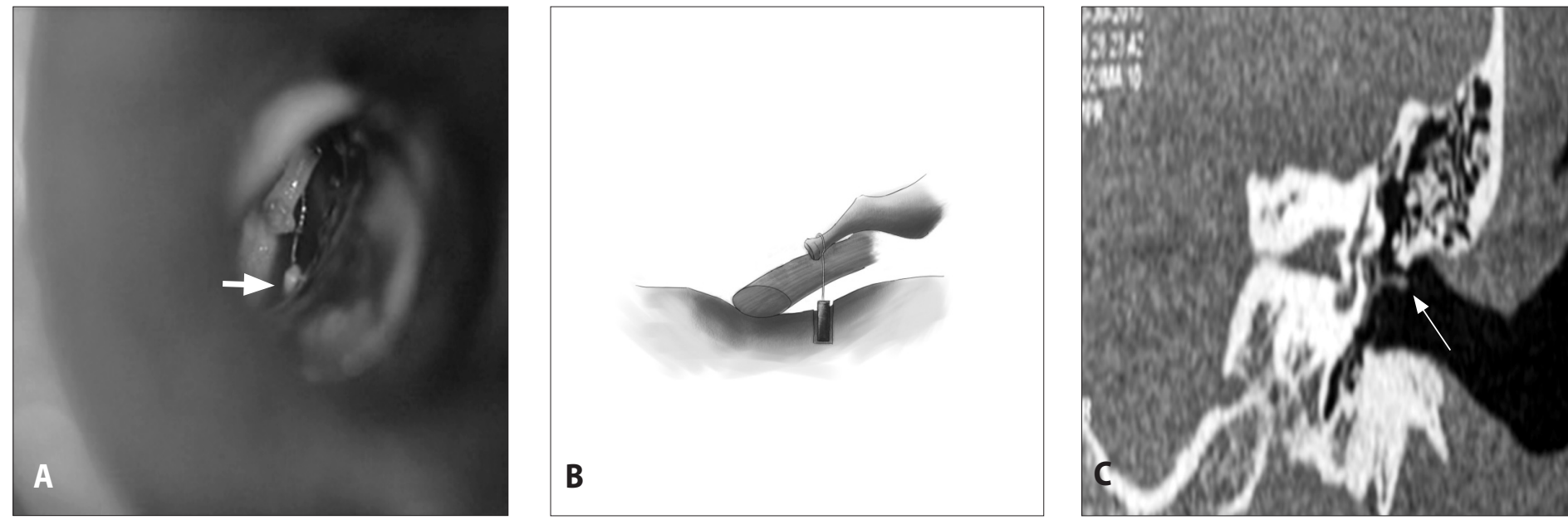

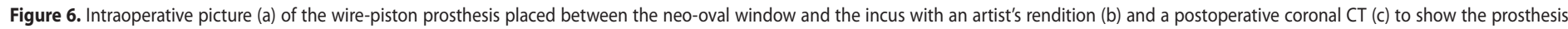
placement (arrow) for hearing reconstruction.

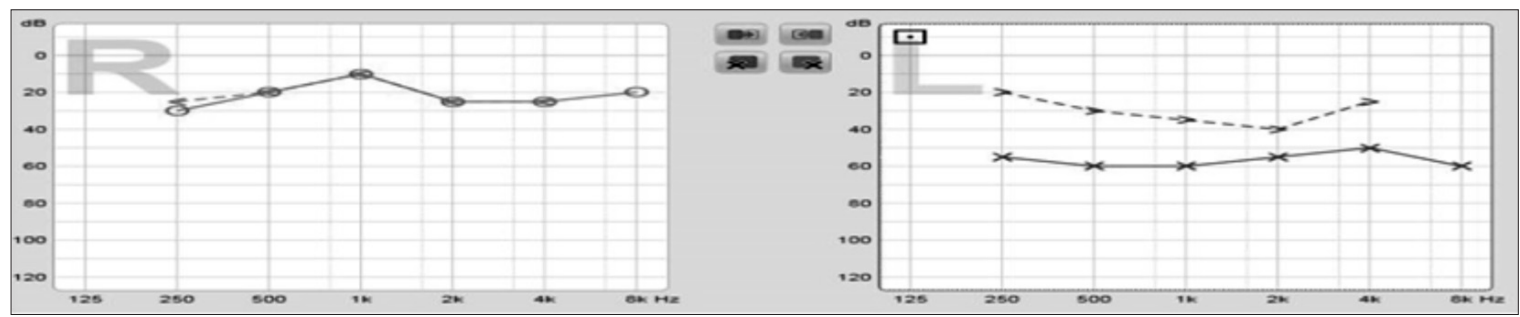

Figure 7. Postoperative audiogram of the patient at six months has remained stable over two years showing AB gap closure within $25 \mathrm{db}$

and tympanometry is used to assess the ipsilateral ear, the type of hearing loss, severity of the hearing impairment and the status of the contralateral ear. The presence of bilateral involvement will necessitate more aggressive management for hearing amplification in children to optimize language learning and speech production at the earliest time. Surgical management hinges on high resolution temporal bone imaging with coronal and axial bone window cuts or multiplanar reformatting to evaluate the oval window or absence thereof as well as the facial nerve course and the ossicular structures as these may predict possible complications. ${ }^{5,6} \mathrm{An}$ MRI study may delineate concomitant inner ear anomalies and rule out tumors or other conditions within the inner ear that can give rise to inner ear conductive hearing loss. Subtle anomalies of the ossicles may still be missed on computed tomography such that an exploratory tympanotomy will be more definitive. ${ }^{1,5}$ Future use of cone beam CT scanning will be of significant value in giving higher resolution images though this is still of limited availability in our country as in other developing countries.

Table 1 summarizes the reports of several authors on various methods for hearing improvement ranging from the most conservative approach such as conventional hearing aids to more invasive approaches such as malleostapedotomy or incudostapedotomy following oval window drill out or platinotomy orvestibulotomy and shows the studies where details on the laterality as well as the surgical technique utilized..$^{5-11} \mathrm{~A}$ variety of prosthesis such as a Teflon piston, and a cartilage columella have been used. ${ }^{6}$ Thomeer's report published in 2012 provided a summary of 70 cases in several series from 1950-2010 mostly comprising Class 1-3, with the largest series of 144 cases reported from Nijmegen by Cremers and colleagues while only ten percent (14 patients from 1986-2001) of cases were of the rarest class $4 a$ type anomaly. ${ }^{10}$ The preferred surgical approach was a transcanal approach, with the creation of a neo-oval window or vestibulotomy and malleostapedotomy comprising the most common procedures utilized, though incudostapedotomy have also yielded good postoperative outcomes in the immediate and long term postoperative period. ${ }^{10}$ Surgical outcomes range from complicated postoperative profound sensorineural hearing loss to significant long term closure of air bone gaps up to ten years. ${ }^{11,12}$ The possibility of iatrogenic sensorineural hearing loss from inner ear damage or facial nerve injury though transient have also been described. ${ }^{9}$ Given this, 
CASE REPORTS

Table 1. Summary of reports on surgery for congenital oval window aplasia.

\begin{tabular}{|c|c|c|c|c|}
\hline Author, Year Published & $\begin{array}{l}\text { Number of Ears with } \\
\text { Oval Window Agenesis/ } \\
\text { Aplasia }\end{array}$ & Unilateral/ Bilateral Cases & $\begin{array}{l}\text { Percentage of ears with } \\
\text { facial nerve anomaly }\end{array}$ & Remarks/Surgical Outcome \\
\hline Ardah, 1996 & $\begin{array}{l}1 \\
\text { *only the right ear was } \\
\text { explored }\end{array}$ & $\begin{array}{l}\text { Bilateral } \\
{ }^{*} \text { cannot be determined }\end{array}$ & $\begin{array}{l}\text { dehiscent bony canal of } \\
\text { the facial nerve }\end{array}$ & $\begin{array}{l}\text { Incudostapedotomy, bur } 0.7 \mathrm{~mm} \text { hole plus teflon } \\
\text { piston }(0.6 \mathrm{~mm} \times 4.5 \mathrm{~mm}) \text { and periosteal graft around } \\
\text { the piston; Hearing gain of } 40 \mathrm{~dB} \text {, stable over three } \\
\text { years follow-up }\end{array}$ \\
\hline Martin et al.,2006 & 4 & Bilateral: 2 & $100 \%$ & $\begin{array}{l}\text { Case } 1 \\
\text { Incudostapedotomy. 0.8-mm platinotomy plus } 0.8 \text { - } \\
\text { mm Teflon piston } \\
\text { Case } 2 \\
\text { Incudostapedotomy, } 0.4-\mathrm{mm} \text { hole drilled under facial } \\
\text { nerve and Fisch piston } \\
6 \text { months later contralateral } 0.4-\mathrm{mm} \text { hole drilled over } \\
\text { facial nerve and } 0.4-\mathrm{mm} \text { Teflon-wire piston clipped on } \\
\text { incus long process }\end{array}$ \\
\hline Esteves et al.,2013 & $\begin{array}{l}6 \\
{ }^{*} \text { Case } 5 \text { - stated "bony } \\
\text { blades into the oval } \\
\text { window" }\end{array}$ & $\begin{array}{l}\text { Unilateral: } 2 \\
\text { Bilateral: } 2\end{array}$ & $50 \%$ & $\begin{array}{l}\text { Case } 1 \\
\text { bilateral BAHA with subsequent hearing gain } \\
\text { Case } 2 \\
\text { conventional bilateral hearing aids with auditory } \\
\text { gain } \\
\text { Case } 3 \\
\text { No auditory rehabilitation, with outpatient } \\
\text { surveillance } \\
\text { Case } 4 \\
\text { Conventional prosthesis was chosen }\end{array}$ \\
\hline Ahn et al., 2013 & 3 & $\begin{array}{l}\text { Unilateral: } 1 \\
\text { Bilateral: } 1\end{array}$ & $100 \%$ & $\begin{array}{l}\text { Case } 1 \\
\text { malleostapedotomy via endaural approach on second } \\
\text { surgery, facial nerve rolled, } 0.6-\mathrm{mm} \text { window drilled } \\
\text { using } 0.4-\mathrm{mm} \text { Skeeter drill, piston wire prosthesis } \\
\text { bent } 20^{\circ} \text {, modified to } 7 \text {-mm length and fixed on } \\
\text { normal malleus } \\
\text { Case } 2 \\
\text { stapedotomy after "facial roll" and } 0.6-\mathrm{mm} \text { window } \\
\text { using } 0.4-\mathrm{mm} \text { Skeeter drill, piston wire } 7-\mathrm{mm} \text {-long } \\
\text { used, transient House-Brackmann Grade III recovered } \\
\text { by } 1 \text { month }\end{array}$ \\
\hline Kutluhan et al., 2010 & 2 & $\begin{array}{l}\text { Unilateral: } 2 \\
\text { Bilateral: } 0\end{array}$ & $50 \%$ & $\begin{array}{l}\text { Case } 1 \\
\text { Vestibulotomy using a pick then teflon prosthesis } \\
\text { Case } 2 \\
\text { tragal cartilage, incus long process with bone cement } \\
\text { as complex at footplate, postoperative hearing gain } \\
42 \mathrm{~dB} \text { and air conducting hearing level } 20 \mathrm{~dB} \text { on right } \\
\text { side }\end{array}$ \\
\hline Thomeer et al., 2012 & 10 & *cannot be derived & $90 \%$ & $\begin{array}{l}\text { Transcanal approach for exploratory tympanotomy } \\
\text { and malleostapedotomy, hearing improved but } \\
\text { deteriorated in long term }\end{array}$ \\
\hline Hasegawa et al., 2012 & 4 & $\begin{array}{l}\text { Unilateral:1 } \\
\text { Bilateral :2 }\end{array}$ & $100 \%$ & $\begin{array}{l}\text { Inner ear fenestration in } 3 \text { followed by piston; } \\
\text { exploratory tympanotomy only in } 1 \text {; hearing improved } \\
\text { in all cases after surgery and to within } 25 \mathrm{db} \text { in two } \\
\text { and within } 45 \mathrm{db} \text { in one }\end{array}$ \\
\hline
\end{tabular}




\section{CASE REPORTS}

both conventional hearing aids and passive or active bone conduction devices remain viable options, especially in bilateral cases., ${ }^{73}$ Long term hearing improvement has been notable in these novel active bone conduction devices in recent reports. ${ }^{12}$ For unilateral cases, no consensus has been reached but recent literature points to a more aggressive approach that involves surgically correcting the unilateral loss for better hearing in noise and sound localization. Some have reported repeated surgeries before attaining a successful outcome, highlighting the risk of failure when doing procedures for such rare conditions. ${ }^{1}$ Though surgery for otosclerosis provided ample experience for doing the reconstruction in other centers the rarity of otosclerosis in the Philippines makes this surgery even more challenging. Facial nerve injury (transient or permanent) deserves consideration in preoperative decision. Intraoperative monitoring of the facial nerve was not discussed in most reports but was considered important in cases where an aberrant course or branching of the facial nerve is suggested on the preoperative $\mathrm{CT}$ scan. ${ }^{14}$ The use of neuromuscular blocking agents are best limited to induction of anesthesia so that electrical stimulation can map out the actual course and functionality of the facial nerve. This may help avoid injury while the nerve is being manipulated in order to insert a prosthesis after making a neo-oval window, as in this case. There are reports of postoperative facial nerve paresis that could have been avoided had intraoperative facial nerve monitoring been done., ${ }^{39}$ Moreover, worse postoperative hearing needs to be honestly discussed. Should the incus be short or abnormal then malleostapedotomy can be performed instead of an incudostapedotomy. The use of a piston wire prosthesis with an incudostapedotomy proved successful in this patient but he continues to be monitored for the possible need for both active and passive middle ear or bone conduction devices. These options remain open though cost considerations in the setting of a developing country remain formidable. The status of hearing in the contralateral ear provides a major impact on the decision with respect to surgery, given that binaural benefit with such passive or active bone conduction devices is achievable only if contralateral hearing remains normal. On the other hand, ossicular chain reconstruction following a neo-oval window and prosthesis placement that provides postoperative hearing within $30 \mathrm{~dB}$ of the good contralateral ear in this case and $A B$ gap closure to within $25 \mathrm{~dB}$ rendered subjective benefit well appreciated by this patient. However, it has been emphasized that a $15 \mathrm{~dB}$ inner ear conductive deafness that remains in these patients would be another limiting factor in the success of $A B$ gap closure in these patients. The presence of other syndromes may also affect the outcomes of hearing reconstruction but this issue remains controversial given the contrasting reports of their impact on hearing results. ${ }^{12,15}$
The continued development of bone conduction devices and middle ear implants can improve outcomes such that the surgical choices will likely expand. Improved diagnostic imaging may also aid in evaluating failures in surgery such as a round window atresia with the potential to be missed or evidence of prosthesis or implant displacement so that the feasibility of revision will be better informed. Ultimately the patient's active role in the decision making must be based on a discussion of all options as illustrated in this adult patient with only unilateral involvement.

\section{REFERENCES}

1. Quesnel S, Benchaa T, Bernard S, MartineF, Viala P, Abbeele TVD, Teissier N. Congenital middle ear anomalies: Anatomical and functional results of surgery. Audiol Neurotol. 2015; 20(4):237242.

2. Teunissen EB, Cremers WR. Classification of congenital middle ear anomalies. Report on 144 ears. Ann Otol Rhinol Laryngol. 1993 Aug;102(8 Pt 1):606-12.

3. Sterkers $J M$, Sterkers $O$. Surgical management of congenital absence of the oval window with malposition of the facial nerve. Adv Otorhinolaryngol. 1988;40:33-7184.

4. Jahrsdoerfer RA. Congenital malformation of the ear: analysis of 94 operations. Ann Otol Rhinol Laryngol. 1980 Jul-Aug;89(4 Pt 1):348-52.

5. Esteves SD, Silva AP, Coutinho MB, Abrunhosa JM, Almeida e Sousa C. Congenital defects of the middle ear--uncommon cause of pediatric hearing loss. Braz J Otorhinolaryngol. 2014 MayJun;80(3):251-6.

6. Kutluhan A, Salviz M, Çetin H, Bilgen AS. Two unusual case of congenital conductive hearing loss related to anomaly of stapes. Cumhuriyet Med J. 2010; 32(3):345-51.

7. Ardah NM. Congenital absence of oval window. Ann Saudi Med. 1999 Nov-Dec;19(6):536-8

8. Martin C, Oletski A, Bertholon P, Prades JM. Abnormal facial nerve course associated with stapes fixation or oval window absence: report of two cases. Eur Arch Otorhinolaryngol.2006 Jan; 263(1):79-85.

9. Ahn SH, Kim DH, Choi JY, Kim BG. Two cases of malleostapedotomy in congenital oval window atresia. Korean J Audiol. 2013 Dec; 17(3):152-155.

10. Thomeer H, Kunst H, Verbist B, Cremers C. Congenital oval or round window anomaly with or without abnormal facial nerve course: surgical results for 15 ears. Otol Neurotol. 2012 Jul;33(5):779-84.

11. Hasegawa J, Kawase T, Hidaka H, Oshima T, Kobayashi T. Surgical treatment for congenital absence of the oval window with facial nerve anomalies. Auris Nasus Larynx. 2012 Apr;39(2):249255.

12. Snik AF, Mylanus EA,Cremers CWR. Speech recognition with the bone-anchored hearing aid determined objectively and subjectively. Ear Nose Throat J. 1994 Feb;73(2):115-117.

13. Agterberg MJH, Hol MKS, Cremers CWR, Mylanus EAM, van Opstal J, Snik AFM. Conductive hearing loss and bone conduction devices: Restored binaural hearing? Adv Otorhinolaryngol. Basel, Karger, 2011:71:84-91.

14. Takahashi H, Kawanishi M, Maetani T. Abnormal branching of the facial nerve with ossicular anomalies: report of two cases. Am J Otol. 1998 Nov;19(6):850-53.

15. Cremers CWR, Teunissen E. The impact of syndromal diagnosis on surgery for congenital minor ear anomalies. Int J Pediatr Otorhinolaryngol. 1991 Jul;22(1):59-74. 